\title{
Maximizing airborne delay at no extra fuel cost by means of linear holding
}

\author{
Yan Xu, Ramon Dalmau, Xavier Prats \\ Technical University of Catalonia, Castelldefels 08860, Barcelona (Spain)
}

\begin{abstract}
This paper introduces a linear holding strategy based on prior works on cruise speed reduction, aimed at performing airborne delay at no extra fuel cost, as a complementary strategy to current ground and airborne holding strategies. Firstly, the equivalent speed concept is extended to climb and descent phases through an analysis of fuel consumption and speed from aircraft performance data. This gives an insight of the feasibility to implement the concept, differentiating the case where the cruise flight level initially requested is kept and the case where it can be changed before departure in order to maximise the linear holding time. Illustrative examples are given, where typical flights are simulated using an optimal trajectory generation tool where linear holding is maximised while keeping constant the initially planned fuel. Finally, the effects of linear holding are thoroughly assessed in terms of the vertical trajectory profiles, range of feasible speed intervals and trade-offs between fuel and time. Results show that the airborne delay increases significantly with nearly 3 -fold time for short-haul flights and 2-fold for mid-hauls to the cases in prior works.
\end{abstract}

Keywords: air transportation, linear holding, speed reduction, trajectory optimization, air traffic flow management

\section{Introduction}

Ground holding, the practice of delaying the take-off of a flight due to anticipated congestion at the destination airport (or at some airspace along the route), is motivated by the fact that it is less expensive and safer than holding in the air (Richetta (1991)). By less expensive, it means less fuel is consumed waiting at the apron with the engines off than delaying the 
aircraft in the air by means of holding stacks or path stretching instructions given by air traffic control (ATC). By safer, it means that the aircraft is not burning (reserve) fuel unnecessarily and by the fact that ATC workload is decreased in the airspace(s) where aircraft are required to lose time. Waiting on ground, however, has the inconvenience that if the delay is no longer necessary and thus cancelled before initially planned (due to the unexpected improving of congestion or weather for instance) (Cook and Wood (2010); Ball et al. (2010); Inniss and Ball (2004)), the grounded aircraft are still at departure airports and the already delayed time on departure cannot be recovered (or can be partially recovered by increasing flight speed, leading to extra fuel consumption if compared with the initially planned flight).

To overcome this issue, a speed reduction strategy was proposed by Delgado et al. (2013) where aircraft were allowed to cruise at the lowest possible speed in such a way the fuel consumption remained exactly the same as initially planned. In this situation, if the delays are cancelled ahead of schedule, aircraft already airborne and flying slower, can speed up to the initially planned and recover part of the delay without extra fuel consumption. Previously, this strategy was explored by Prats and Hansen (2011), but aimed at partially incurring in the air, by flying slower, the assigned ground delays. Ground delayed aircraft were enabled to fly at the minimum fuel consumption speed (typically slower than nominal cruise speed initially chosen by the airline), performing in this way, some airborne delay at the same time fuel was saved with respect than the nominal flight. Thereafter, more related work to the strategy has been done discussing such as the impact to Ground Delay Programs (GDPs), the effects from en route wind and the potential applicability for handling air traffic flow (Delgado and Prats (2014, 2013, 2012)).

Other than the typical airborne delay (holding pattern or path stretching), this kind of linear holding means that only speed is adjusted and the planned route remains the same. Furthermore, in line with the concept of trajectory based operations (TBO), as proposed in SESAR and NextGen programs, delays could be allocated in form of controlled times of arrival (CTA) at different designated waypoints along the route (Klooster et al. (2009); Smedt et al. (2013)). In this way, linear holding could be seen as a complementary air traffic flow management (ATFM) strategy, in addition to ground holding, pre-tactical re-routing or strategic deconfliction initiatives (Ruiz et al. (2014)). Then, through a dynamic speed management along the route, the arrival time at different waypoints could be tactically adjusted in 
response to uncertainties.

As the core method to perform linear holding, speed reduction is essentially one of the speed control methods that have proven successful for several air traffic management (ATM) scenarios. For instance, Jones et al. (2013, 2015) presented a speed control approach for transferring delay away from the terminal to the en route phase, from which significant fuel saving on a per flight basis was also yielded. In Günther and Fricke (2006), a pre-tactical speed control was applied en route to prevent aircraft from performing airborne holding patterns when arriving at a congested airspace, with both flight efficiency and controller workload reported improved. Similar but more at tactical level, aircraft in Australia (2007) were required to reduce their speed to avoid arriving at the airport before its opening time to reduce unnecessary holdings. More widely, the applicability of speed control with regard to the conflict resolution problem has been discussed for decades, and typically it was implemented along with other approaches such as path changing (Tomlin et al. (1998)) or flight level assignment (Vela et al. (2009)). With metering operations under TBO, aircraft trajectories are tactically managed to their schedules across meter points, through speed control or path extension based on accurate trajectory predictions and modifications, which raises the critical need of concern about uncertainties (such as aircraft-specific parameters and predicted winds), as has been studied in Kirkman et al. (2014). Regarding terminal procedures (where aircraft are typically climbing or descending), however, speed control has been mainly used for (tactical) separation purposes. (see for instance in Barmore (2006); Xu et al. (2016)).

This paper extends the work done in Delgado and Prats (2012); Delgado et al. (2013); Delgado and Prats $(2013,2014)$ by proposing a linear holding strategy that not only takes into account the cruise phase, but also considers climb and descent phases The inclusion of climb and descent will increase the overall capability of delay absorption and even make it appealing for shorthaul flights, as climb and descent often represent a considerable percentage of the total trip distance. Through the use of aircraft trajectory optimization techniques, the differences on efficiency of performing linear holding during each flight phase will be fully utilized, in such a way to generate the optimal trajectory realizing the maximum airborne delay. Since changes of flight trajectory have a direct effect to fuel consumption, which is one of the main safety issues and operating costs airlines have concerns about (Cook and Tanner (2011)), this maximum airborne delay is computed with the precondition that the delayed flight must burn the same (or less) quantity of fuel 
than the original flight, when planned before receiving the ATFM regulation.

\section{Linear holding at no extra fuel cost}

Current on-board flight management systems enable airlines to optimize the aircraft trajectory in terms of DOC (Direct Operating Costs, including both fuel and time related costs) (Airbus (1998)) by means of the Cost Index (CI), which represents the ratio between time-based cost and the cost of fuel (Roberson and Pilot (2007)). In this paper, optimal trajectories computed with a given CI would be regarded as the nominal flights, and labeled as Case-0.

\subsection{The linear holding concept}

In order to explain the LH concept, it is appropriate to start with a short comparison between the two commonly seen holding practices in current ATM: ground and airborne holding, along with the proposed cost based linear holding, as shown in Fig. 1.

Place Fig. 1 about here.

In terms of fuel consumption, typical airborne holding would consume more fuel due to the extended flight track (the deviation of actual trajectory to the initially planned) (Belkoura et al. (2016)), whilst holding on the ground should make no difference with the planned fuel. For LH a trade-off is possible between fuel and time, depending on the speed adjustment strategy.

Due to the increased extra fuel, the airborne holding time is fairly limited if compared with ground holding, taking account that safety related issues may arise from a reduction of the on-board reserve fuel. On the other hand, the LH time should depend on several factors, such as aircraft type, flight distance, payload, cruise flight level, etc., and requires a detailed analysis (as done in Sec. 3 of this paper). Although a reasonable amount of extra fuel allowance could bring a considerable increase of the maximum LH time, this option is out of the scope of this paper and the pre-condition is that LH must be done at no extra fuel cost.

From the implementation point of view, ground holding can be only performed at departure airport, prior to take-off, while the airborne holding, technically, can be realized at any available airspace during the flight, but practically due to the constraints from ATM (FAA (2015)), it is typically performed in specific designated airspace, which differs from the LH that is done progressively along the original planned route. 
Generally, as indicated from the comparison, the most promising feature of $\mathrm{LH}$ is that the amount of airborne delay absorption can be flexibly managed along the flight trajectory, and without incurring extra (safety related) onboard fuel than initially scheduled. With the paradigm shift of an airspacebased ATM to the trajectory based operations, the proposed LH could be integrated into the four dimensional aircraft trajectory for the purpose of dynamic delay management.

Following this thought, the paper aims to identify the maximum delay absorption that can be realized by LH (at no extra fuel cost). Performing LH lower than this maximum bound, it will be cheaper and safer than typical airborne holding, and can be used as a complementary strategy to ground holding when airlines scheduling their delayed flights. In this situation, the departure time can remain as close to the original plan as possible, and thus a more smooth flight schedule will be guaranteed, if compared with the case in which the entire assigned delay is imposed on ground holding.

Apart from these and the benefits mentioned in Sec. 1, as previously analyzed in detail in Delgado et al. (2013); Delgado and Prats (2014), more potential applicability can be expected. For instance, it can be combined with the airline strategy of wait-for-passengers (only in case delay is recovered), i.e., deciding to actively delay outbound flights at the hub to ensure that connecting passengers do not miss their connections (see Delgado et al. (2016)). In addition, through substituting part of the ground holding by a flexible LH, the additional delays (see Bilimoria (2016)) raised from the lack of coordination among multiple traffic management initiatives can be reduced remarkably (Xu and Prats (2017)). Nevertheless, further discussion on the detailed application is out of the scope of this paper. To have a clear objective, the following sections are devoted to justify the maximum delay absorption by LH and to analyze the corresponding effects brought to particular flights.

\subsection{Different linear holding implementations}

Based on Case-0, three additional Cases using the LH strategy will be analyzed in this paper and explained in this section.

\subsubsection{Case-1: LH in cruise phase maintaining the nominal flight level}

Typical operating cruise speeds are higher than the MRC (Maximum Range Cruise) speed (i.e. the speed corresponding to $\mathrm{CI}=0$ ). Accordingly, 
the cruise specific range (i.e., SR, the distance flown per unit of fuel consumed) is lower than the maximum for that altitude. In Delgado and Prats (2012); Delgado et al. (2013); Delgado and Prats (2013, 2014) this Case was already explored and the authors defined an equivalent speed $v_{e q}$ as the minimum speed yielding the same $\mathrm{SR}$ as flying at the nominal speed $v_{0}=v_{E C O N}$, as shown in Fig. 2. Therefore, for all cruise speeds between $v_{e q}$ and $v_{0}$, the fuel consumption will be the same or lower than initially planned while LH can be performed when cruising. This case is repeated in this paper for comparison purposes.

Place Fig. 2 about here.

The margin between $v_{0}$ and $v_{e q}$ is a function of both nominal CI and the shape of the SR curve, which in turn is aircraft, flight level and mass dependent. Moreover, it is still worth noting that $v_{e q}$ might be limited by the minimum operational speed of the aircraft at that given flight level and mass (including possible safety margins). For the LH strategy presented in this paper, however, the Green Dot (GD) speed is adopted as the minimum bound, which depicts the best lift to drag ratio speed in clean configuration.

The lowest selectable speed $V_{L S}$ (defined as $1.3 V_{S}$ ) can be manually selected by the pilot and it is lower than the GD speed (Airbus (1993a)). Yet, considering the operability of the LH strategy and aiming at automatic flight managed by the flight management system (FMS), it is more realistic to choose GD, which is the lowest speed the FMS can choose (Airbus (1993b)).

\subsubsection{Case-2: LH in climb, cruise and descent phases maintaining the nom- inal flight level}

Not only is the cruise phase affected by CI, but also climb and descent profiles. According to the definition of CI, with its increasing, more importance will be given to the time-related costs, rather than the costs of fuel, which means higher speeds would be favored despite of the added fuel to be burned. These trade-offs within the climb and descent phases can be seen in Fig. 3, which depicts a schematic of curves computed with the Performance Engineering Program (PEP) of Airbus for an A320 aircraft model at a typical take-off mass. Seeing from the figure, there exists a minimum-fuel speed at the bottom of the function curve (for each flight level), and by accelerating or decelerating from that speed more fuel is needed.

Place Fig. 3 about here.

Thus, the LH strategy could be extended to the whole flight and not just in the cruise phase. A similar behavior than in cruise occurs for climb and 
descent phases when a CI higher than 0 is selected by the operator: the climb (descent) speed is faster than the minimum fuel speed, and there exists an equivalent speed yielding to the same fuel consumption as initially planned. Therefore, for all speeds within the shadowed intervals of Fig. 3, the fuel consumption will be the same or lower than the nominal case, while LH will still be performed.

Moreover, since the angle of climb (descent) varies with speed, the climb (descent) distances will be different at different speeds, meaning that the location of the top of climb (TOC) and top of descent (TOD) will depend on these speeds. The vertical flight profiles should then change with the variation of speeds too. For instance, by flying higher speeds, the climb profile becomes shallower, while conversely the descent profile turns steeper (see Fig. 4) (Airbus (1998)).

Place Fig. 4 about here.

In order to specify a common reference framework to define what is the climb and the descent phase, as with different climb and descent profiles the distance when TOC and TOD are reached might vary, a reference (Ref.) TOC or Ref. TOD, fixed at a given geographical distance, is assumed as shown in Fig. 4. In this figure, the red line denotes a short cruise segment whose length depends on the (speed dependent) distance between the original TOC (TOD) and the Ref. TOC (TOD).

According to the Airbus manual (see Airbus (1998)), this short cruise segment can be calculated as the difference between the "low cost index TOC/TOD" and the "high cost index TOC/TOD". By the same thought, the geographical point of the Ref. TOC (TOD) for a particular flight level is assumed, in this paper, as the maximum distance flown with regard to all feasible speeds when ascending up to (or descending down from) that particular altitude (e.g., climb profile c and descent profile d in Fig. 4, which corresponds to the longest climb and descent distance respectively, as stated in Airbus (1993a)).

Place Fig. 5 about here.

Nonetheless, in real operations this climb/descent speed is not constant, due to operational or ATM constraints. Unlike in cruise, where flight is performed at a constant Mach number, the climb is divided into several speed segments. These normally include a speed limitation at low altitudes, typically 250kt CAS below FL100, followed by an acceleration process to a constant CAS climb, finally followed by a constant Mach climb above the crossover altitude. The same segments are for descent, but with the opposite 
order.

Fig. 5 shows an example for such a climb/descent speed profiles $(250 \mathrm{kt}$ /300kt /M0.78) with a solid black line. Nominal flights for CI greater than zero will lead to climb and descent speed profiles as shown by the red line, while the blue line denotes the equivalent climb/descent speed profile, which maximizes linear holding but might be limited by the lower speed bound (GD speed).

\subsubsection{Case-3: LH in climb, cruise and descent phases and optimizing for cruise flight level}

In general, as the cruise speed reduces, the optimal flight level decreases (see from Fig. 6 the SR changes with flight levels computed with PEP for an Airbus A320 at a typical take-off mass). Since the equivalent cruise speed is lower than the nominal cruise speed, it is possible that the initial planned flight level is no longer the optimal one in the LH Cases. Thus this case allows freedom to the trajectory planning tool to choose the best cruising flight level(s) such that the linear holding is maximized, but as always, the total fuel consumption is equal or below the nominal fuel consumption (Case$0)$.

Place Fig. 6 about here.

Recall the discussions about incorporating LH strategy to climb and descent phases in Sec. 2.2.2. It can be understood that a lower cruise flight level may produce a lower LH time in climb and descent, as the interval between the nominal and equivalent speed that contributes to generating $\mathrm{LH}$ would last for a shorter period (see Fig. 5 for instance). But at the same time save some fuel due to the lower climb and descent altitudes. Conversely, it can generate a higher LH time in cruise phase but consume more fuel (which is also dependent on flight distance). Therefore, as discussed above, it is possible that taking the cruise flight level into the optimization it could bring better results in terms of larger $\mathrm{LH}$.

\section{Simulation setup}

This section introduces the main features of the tool used to generate the trajectories shown in this paper, which is an in-house software capable to optimize trajectories for any phase of flight, allowing to setup a wide range of operational constraints and taking into account different optimization crite- 
ria. The optimization objective and constraints (depending on the different LH Cases) are also included in this section.

\subsection{Optimal trajectory generation tool}

The main architecture of this trajectory generation tool is shown in Fig. 7. Given a set of inputs, the trajectory generation tool formulates the optimization of trajectory as a multi-phase constrained optimal control problem, in which it is desired to determine the controls of the aircraft (thrust and flight path angle) such that a given cost function is maximized or minimized while satisfying a set of constraints (Betts (2010)). Further mathematical details on the formulation of optimal control problems for trajectory optimization applications can be found in Dalmau and Prats (2015). The resultant optimal control problem is solved by means of numerical optimization using direct collocation methods, which transform the original continuous (and thus infinite) optimal control problem into a (discrete and finite) nonlinear programming (NLP) optimization problem. The new finite variable NLP problem is solved by using solvers CONOPT (as NLP) and SBB as MINLP (mixed integer nonlinear programming), both bundled into the GAMS software suite.

Place Fig. 7 about here.

The formulation of the optimal control problem requires mathematical models capturing aircraft dynamics and performances, along with a model for certain atmospheric variables. The equations of motion are derived for a point-mass aircraft model (three degrees of freedom) without winds and assuming continuous vertical equilibrium. On the other hand, the generated trajectories rely on propulsion and aerodynamics models developed with accurate aircraft performance data derived from PEP. For the atmosphere, the International Standard Atmosphere (ISA) model is used (Organization (1994)).

In order to guarantee a feasible trajectory, as a result of the optimization process, several constraints must be considered. For instance, the dynamics of the system or generic box constraints on the state and control variables (such as maximum and minimum operating speeds or flight path angles). The remaining constraints of the problem are specified by means of a flight profile. The flight profile is characterized in several user-defined phases, where different path constraints and event constraints may apply reflecting typical ATM practices and operational procedures.

The trajectory generation tool imposes constant Mach, CAS or altitude phases by means of optimization parameters that are bounded with the up- 
per and lower values specified in the flight profile. It should be noted that the optimization algorithm will choose the (optimal) values of the different CAS, Mach and altitude phase dependent parameters, as well as the number of step climbs (if any) to perform. In addition, the solution might satisfy some algebraic event constraints fixing the initial and final conditions of the problem.

\subsection{Trajectory modelling for the different Cases of study}

Following a conventional operation concept, the flight profile is divided into several segments where different models and standard operational procedures apply. Fig. 8 summarizes the flight segments in simulation and the corresponding path and event constraints, being $m$ the step climb index.

Place Fig. 8 about here.

Taking this flight profile as baseline, the nominal flight (see details about nominal trajectory generation in Dalmau and Prats (2015)) and the three LH Cases could be simulated with the in-house tool presented above by properly configuring the input parameters as follows.

For the nominal flights, i.e., Case-0, the objective of the optimization is minimizing the compound cost function consisting of fuel $F_{i}$ and time $T_{i}$ for each segment $i$ divided from a whole flight, weighted by the CI:

$$
\min \left(\sum F_{i}+C I \cdot T_{i}\right)
$$

For the LH flights, i.e., Case-1, -2 and -3, the general optimization objective is changed to maximize the total flight time, Eq. 2, while subject to the basic constraint of fuel consumption as depicted in Eq. 3:

$$
\begin{gathered}
\max \sum T_{i} \\
\text { s.t. } \sum F_{i} \leq F_{\text {nom }}
\end{gathered}
$$

where $F_{n o m}$ is the fuel consumption in nominal flight.

This makes it clear that the flight as a whole is optimized rather than the climb, cruise or descent phases separately. Although some trade-off between fuel consumption and time (speed) within each phase can be found, the trade-off between the three phases should be considered as well, which may contribute to better LH results. 
Since Case- 1 the LH is implemented only in cruise phase the optimization process only considers segments between $S C_{1}$ and $S C_{m+2}$ (inclusive) as shown in Fig. 8. For this Case the climb and descent phases are fixed to those of the nominal flight. Therefore, only the speed in cruise is subject of optimization. In addition, the following constraints must be enforced at both initial and final points of each step climb segment $C R_{2 m}$ (if any), where $H$ and $D$ denote the flight level and distance respectively, in order to preserve the vertical profile of the nominal cruise phase:

$$
H_{\text {Case-1 }}^{C R_{2 m}}=H_{\text {Case-0 }}^{C R_{2 m}}, D_{\text {Case-1 }}^{C R_{2 m}}=D_{\text {Case-0 }}^{C R_{2 m}}
$$

In Case-2: the LH is extended to include climb and descent phases but keeping unchanged the nominal cruise flight level (or flight levels if $m>0$ ). Accordingly, the whole flight (from $C L_{1}$ to $D E_{4}$, see Fig. 8) is subject of optimization. The following constraint must be enforced so that the altitude of both TOC (final point of $C L_{4}$ ) and TOD (initial point of $D E_{1}$ ) remain unchanged:

$$
H_{\text {Case-2 }}^{C L_{4}}=H_{\text {Case-0 }}^{C L_{4}}, H_{\text {Case-2 }}^{D E_{1}}=H_{\text {Case-0 }}^{D E_{1}}, H_{\text {Case-2 }}^{C R_{2 m}}=H_{\text {Case-0 }}^{C R_{2 m}}
$$

The distance at which each step climb (if any) is performed is no longer enforced, considering that possible changes in the TOC and/or TOD positions could impact on the length of the different cruise segments. In addition, it should be noted that an upper bound must be set for the aircraft mass at the initial point of $C L_{1}$, in such a way to stipulate the fuel consumption not exceeding than initially scheduled.

Finally, for Case-3, the LH is implemented in the whole flight in the same manner as Case-2. In this case, however, only the constraint of fuel consumption is enforced, allowing the solver to optimize also the cruise altitude(s). Taking the realistic limits of available altitudes into consideration, specific constraints on the range of flight levels could be enforced as well.

It is worth noting that the decision to perform LH is taken at dispatch level, when planning the flight before take-off. Thus, the new submitted flight plan might always be subject to ATM clearance, especially for Case-3, where changes in requested flight level(s) are involved. Recall the SESAR concept of Reference Business Trajectory (RBT), which the airspace user agrees to fly and the ANSP (air navigation service provider) and airports agree to facilitate (Klooster et al. (2010)). Then, the three Cases will be able to provide alternative options for airlines to plan their flights. For instance, 
if Case-3 is eventually not agreed, the operator can choose Case- 2 where the flight level(s) is(are) fixed as initially scheduled (and agreed). Eventually, it might occur that heavy constraints in terminal airspace would not allow Case-2, so in this instance the operator can still select Case-1 which performs LH only in the cruise phase. This paper, therefore, presents the maximum delay absorption, by means of LH, for all the above three Cases.

\section{Illustrative Examples}

In this section some illustrative examples are given analyzing the amount of LH that can be achieved for six representative routes (Sec. 4.1). In Sec. 4.2 a specific flight FRA-MAD with $\mathrm{CI}=60$ is studied in detail with numerical values for the resulting speed profiles for climb, cruise and descent, respectively.

The six flight routes studied in this paper are: DUB (Dublin, Ireland) LHR (London Headrow, United Kingdom): 243nm; FCO (Rome Fiumicino, Italy) - CDG (Paris Charles de Gaulle, France): 595nm, FRA(Frankfurt, Germany) - MAD (Madrid, Spain): 769nm; AMS (Amsterdam, The Netherlands) - SVQ (Seville, Spain): 1000nm; STO (Stockholm, Sweden)-ATH (Athens, Greece): 1305nm; and LIS (Lisboa, Portugal) - HEL (Helsinki, Finland): $1819 \mathrm{~nm}$; all of which are representative of short/mid haul flights in Europe. Each route is further analyzed with different CI ranging from 5 to $150 \mathrm{~kg} / \mathrm{min}$ with an Airbus A320, a common two-engine, narrow-body transport aircraft.

Some assumptions have been taken for all simulations: 1) The identification of flight phases is based on Ref. TOC/TOD (see Fig. 4) instead of TOC/TOD; 2) Great Circle Distance (GCD) is considered between origin and destination airports, instead of considering air traffic services routes; 3 ) a passenger occupation (payload factor) of $81 \%$ is considered for all flights (Delgado and Prats (2012)); 4) no wind conditions are considered; 5) alternate and reserve fuel are not modeled; 6) only even flight levels are used (FL260 as the lowest altitude); and 7) cruise step climbs are allowed with $2000 \mathrm{ft}$ steps and 5 minutes as minimum time for each flight level.

\subsection{Results}

This section presents the results of applying the three LH strategies to the six routes under study and for the different Cost Indexes considered. 


\subsubsection{Trip fuel and trip times}

Place Fig. 9 about here.

Seeing from Fig. 9, the airborne delay for Case-2 is always greater than that of Case-1, since in the former LH is also allowed in the climb and descent phases. The benefits of this strategy are more noticeable for short flights, since the percentage of the climb/descent phases with respect to the whole flight is higher. It is worth noting, that in some flights (especially for higher CIs) the LH of Case-2 is more than 2-fold the LH of Case-1. This highlights the importance of including the climb and descent phases into the LH strategy.

Differentiating from Case-2 or Case-3, where the achievable airborne delay always grows with the increasing of CI, as can be noticed from Fig. 9, there is, however, a peak value for each route of Case-1, appearing at the CI of $60 \mathrm{~kg} / \mathrm{min}$. Remember in Case-1, the cruise phase is the only flight segment that is subject to LH strategy. By selecting higher CI, more fuel will be consumed during the whole trip of the nominal flight (Case-0), and thus an increased amount of fuel will be allowed to perform LH, leading to a growth of airborne delay (as in Case-2 and Case-3). But as discussed previously by Fig. 4, higher CI will also affect the vertical flight profile, typically with a flatter climb and a steeper descent. It happens that by selecting CI greater than $60 \mathrm{~kg} / \mathrm{min}$, the cruise distance of the nominal flight, which is then fixed in Case-1, becomes even shorter to realize the LH strategy, and thus contributes to less airborne delay. For detailed analysis about this Case, the readers may refer to Delgado and Prats (2012).

Regarding Case-3 (cruise flight level is also subject to optimization), the amount of airborne delay increases for some flights where the altitude change is feasible. Yet, this increase in LH is not so remarkable as from the comparison between Case-1 and Case-2. This is due to the fact that within the low cruise speeds the SR curves for different cruise flight levels are quite close (see Fig. 6), such that the speed reduction from altitude changes, i.e.,

Case-2 to Case-3, will not be as large as the reduction from nominal speed to equivalent speed, i.e., Case-1 to Case-2.

Place Fig. 10 about here.

On the other hand, Fig. 10 presents the changes of trip fuel of each LH Case during different flight phases, with respect to the nominal flight (Case0 ). In Case- 1 only the cruise phase is subject to performing LH, with the allowable fuel consumption fixed by both the TOC and TOD (see Sec. 3.2), 
such that there should be no difference in the regard of trip fuel if compared with Case-0. Accordingly, only Case-2 and Case-3 are shown in Fig. 10, being their distributed fuel consumption (compared to those in Case-0) appreciated in respectively climb, cruise and descent flight phases.

It can be seen from the figure that different types of transition (among flight phases) of trip fuel might apply for the simulated trajectories. For example, under the condition that the total fuel remains unchanged, there exist flights which save fuel during the climb, use extra fuel during the cruise and descent, flights which use more fuel during climb and descent, save fuel during cruise, and etc. This suggests that the different efficiency of fuel consumption (to generate delays) in each flight phase could enable the optimizer to utilize these differences and produce the best allocation of trip fuel, in order to maximize the achievable airborne delay. Nevertheless, some general rules can be also noticed. For instance, all the trajectories in simulation are observed to consume more fuel in the descent phase, and (only) in Case-3 it seems that the fuel are all saved in the climb phase. A detailed analysis of the possible reasons will be discussed in the following section.

Place Fig. 11 about here.

\subsubsection{Trade-offs between fuel and delay}

The specific trade-off of fuel and delay with respect to the nominal trajectory (Case-0) for each individual flight phase, i.e., climb, descent and cruise, can be seen from Fig. 11. Meanwhile, the detailed distribution of each type of trade-off are also as shown in the respective quadrant of the figure. As discussed in Sec. 2.2, with different climb and descent profiles, the distances when TOC and TOD are reached might vary. In order to have a representative comparison of the differences on fuel consumption and flight time, the Ref. TOC and Ref. TOD might be defined to specify a common reference point, which as shown in Fig. 11 depict respectively the longest and shortest distance of the TOC and TOD appearing within the simulated flights for each route. In addition, to further understand the impacts from that short cruise segment produced by the variation of TOC/TOD, Fig. 11 also presents, by the side of trip fuel and time, the distribution of changes on, such as the TOC, TOD and cruise distance, with regard to the nominal flight.

It can be noticed from the figure that, for almost all the simulated flights, the trip time are extended to achieve some airborne delay during each of the three flight phases (regardless of defining Ref. TOC/TOD or not), even with more fuel or less fuel consumed than the nominal. However, an exception 
occurs in the climb phase (see Fig. 11(a)), where negative airborne delays are generated together with some fuel saved at the same time. Moreover, it applies only when considering the real TOC.

For Case-3, those negative values are mainly due to the reduction of the cruise flight level (which is changeable in this Case) that shortens both the climb altitude (i.e., TOC) and the climb distance (see Fig. 11(b) in which all the flights are observed to have a shorter climb distance in Case-3 if compared to Case-0). On the other hand, the fewer exceptions in Case-2 (negative airborne delay and fuel consumption shown in Fig. 11(a)) could be as well due to the shortened climb distance (see also Fig. 11(b)), considering that a lower speed will contribute to less climb distance, leaving the climb time dependent on their quotient. Then, setting a common climb point, i.e., defining the Ref. TOC, would remove all these exceptions, as shown in Fig. 11(a). It can be noticed that, in order to realize some airborne delay, part of the fuel could be saved or extra consumed before reaching that Ref. TOC.

In the descent phase, as shown in Fig. 11(c), the difference on fuel is quite smaller than that in the climb phase (given that the overall fuel consumption of climb should be much larger than in descent), but the airborne delay that can be realized is still remarkable. This suggests that the efficiency of trade-off between trip fuel and time could be higher in descent than in climb, meaning that for the purpose of maximizing airborne delay it could be better to save more fuel in climb and allocate it in descent. This effect can be validated from the results of Case-2 and Case-3 (using TOD) in Fig. 11(c). For all the flights more fuel are burned in descent, with 6 to 12 minutes of airborne delay generated at the same time, although some of such delay may be thanks to the extension of the descent distance (see Fig. 11(d)).

Finally, Fig. 11(e) presents the results of the cruise phase. A slightly difference on fuel can be observed even in Case- 1 when using Ref. TOC/TOD, as it is the real TOC/TOD that are the points fixed for Case- 1 in the simulation. Meanwhile, most of the flights in Case-2 and Case-3 consume more fuel, especially for those in Case-3 (for both using TOC/TOD and Ref. TOC/TOD), which is due to the fact that lower cruise flight level typically brings lower SR (see Fig. 6) that incurs more fuel consumption per unit of cruise distance. Nevertheless, there are several flights in Case-2 that can be seen with a relatively large amount of fuel saved instead, some of which only yield few minutes of airborne delay. This is because, resulted from the combined effect of the movement of TOC and TOD, the real cruise distance could be reduced on some level, as shown in Fig. 11(f). And in Case-3, 
however, the cruise distance is enlarged for all the flights, leading to even more fuel consumed (in addition to the factor that the SR decreases).

\subsubsection{Vertical trajectory profiles}

The vertical trajectories and the corresponding TAS profiles are plotted at the same figure, versus flight distances, as shown in Fig. 12, where the set of flights is categorized with respect to the six flight routes studied and for two different CI (CI=25 and 100 are selected as examples, representing lower and higher CI respectively in this paper).

Place Fig. 12 about here.

For the nominal flights (Case-0), the optimal trajectories are as shown with the red circles in Fig. 12, and due to the fuel burnt en route, step climbs in cruise are observed for long distance flights. It can be also noticed that the higher the CI is, the higher the optimal cruise TAS (red lines) will be.

Since only the cruise phase is subject of LH in Case-1, where climb and descent phases are fixed with the corresponding nominal ones, the trajectories of both Case-1 and Case-0 are exactly the same. The speed profile (black lines), however, differs in cruise as the equivalent speed is adopted instead of the nominal one, between which the gap shows the interval of the speed reduction which realizes $\mathrm{LH}$.

In Case-2, with climb and descent phases included into the LH strategy (but cruise flight level fixed), the trajectories are slightly different from the nominal ones, since the TOC and TOD may move forward or backward as the case may be (blue diamonds). Furthermore, a much larger interval of the speed reduction occurs within the whole flight, compared with Case-1 (blue lines), which, in turn, will produce a remarkable increase on LH time.

With regards to Case-3, as the cruise flight levels are subject of optimization, a decrease on optimal cruise flight level is observed in some trajectories (green squares), which corresponds to the general fact that with speed reducing, the optimal cruise flight decreases simultaneously (see Fig. 6). However, due to the flight level allocation scheme (only discrete flight levels at 2000 ft intervals are allowed), some of the trajectories just keep unchanged as those in Case-2. With CI increasing, an even larger speed reduction from the nominal speed occurs (green lines), compared with the one in Case-2.

\subsection{Detailed trajectory analysis (FRA-MAD with $C I=60 \mathrm{~kg} / \mathrm{min}$ )}

For illustrative purposes, the FRA-MAD flight with $\mathrm{CI}=60 \mathrm{~kg} / \mathrm{min}$, is selected in this section to show the effects that the different LH strategies 
have on the aircraft trajectory (vertical and speed profiles).

\subsubsection{Time and fuel trade-offs}

Aiming at showing the different tradeoffs between time and fuel as a function of the flight distance, Fig. 13 displays, for each LH Case (Case1, Case-2 and Case-3), the difference on flight time (i.e., airborne delay) and fuel consumption with respect to the nominal trajectory (Case-0) along with the execution of the flight. Meantime, Table 1 summarizes from the figure, for each flight phase, the main trip parameters including the fuel, time, average TAS and LH (including specific range and altitude information for the cruise). Note that the identification of the climb/descent phases is based on Ref. TOC/TOD concept.

Place Fig. 13 about here.

Place Table. 1 about here.

Compared with the nominal flight (Case-0), Case-1 consumes almost the same fuel in each phase, while the slightly difference (see Fig. 13(b)) is due to the fact that speed is changing in the short cruise segment (Ref. TOC/TOD) to realize LH and to recover the nominal descent speed. Therefore, the avg. TAS of climb/descent reduces gradually, such that 0.6 and 1.2 minute of LH time are observed in climb and descent, respectively. Then, as Table 1 shows, by shifting to the equivalent cruise speed (99kt less than the nominal one in avg. TAS), 15.5 minutes of LH could be achieved, which accounts for the $21 \%$ of the cruise time and the $12 \%$ of the total time.

The fuel consumption of Case-2 reduces $115 \mathrm{~kg}(29 \%)$ in descent and the LH time is almost 5 minutes in this phase, while another 4.8 minutes is realized in climb phase but only about $7 \mathrm{~kg}(0.3 \%)$ of fuel is saved instead. As shown in Fig. 13(b), since the total trip fuel keeps the same, this $115 \mathrm{~kg}$ of fuel saved from descent plus $7 \mathrm{~kg}$ from climb can be allocated to the cruise phase $(122 \mathrm{~kg}, 6 \%$ increase), which reduces the SR by $0.01133 \mathrm{~nm} / \mathrm{kg}$ and thus further lower the equivalent cruise speed by 35kt, generating 7.7 minutes of extra LH, compared with Case-1. In general, as shown in Fig. 13(a), the total LH in Case- 2 reaches 33 minutes, which accounts for the $23 \%$ of total time, and which is 15.7 minutes more than the one in Case-1 (91\% increase).

As for Case-3, with speed reducing in LH, the optimal cruise flight level for the lower cruise speeds decreases from FL380 to FL360 (see Table 1), leading to $113 \mathrm{~kg}(6 \%)$ of fuel saving in climb while $105 \mathrm{~kg}(39 \%)$ increasing in descent, if compared with Case-2. Although the LH time in climb becomes 0.4 minute less than Case-2, the relatively higher percent of fuel added in 
descent, however, produces 3.3 minutes more instead. Moreover, a slightly increase of fuel with only $7 \mathrm{~kg}(0.0006 \mathrm{~nm} / \mathrm{kg}$ lower in SR) in cruise helps generate 1.9 minutes more LH time than that in Case-2 (compare the curve slopes between Ref. TOC and Ref. TOD in Fig. 13(a)) due to the lower cruise flight level, but its maximum is already approaching as the cruise speed (336kt) is constrained by the GD speed for that flight level. Generally, the total LH time grows 4.8 minutes more than the one in Case-2 (15\% increase).

\subsubsection{Speed profiles and fuel consumption}

In order to better illustrate how the aircraft speed changes in each phase, speed profiles for each of the four Cases of study are plotted in Fig. 14.

Place Fig. 14 about here.

As shown in Fig. 14(a), the climb speed profiles of all the Cases have similar structures, which mainly include a continuous acceleration process at low altitude, a constant CAS climb, followed by constant Mach climb at higher altitudes. At the end of the climb phase a small deceleration is observed in each LH Case, which allows to reach the (slower) optimal cruise speed. Being Case- 0 the baseline, the difference with Case-1 only lays on this deceleration process in cruise, such that the avg. TAS of Case- 1 turns down slightly, leading a reduction on fuel consumption (see Table 1).

In Case-2, the optimizer chooses a climb with CAS around 230kt (instead of the 300kt observed in Case-0). Due to this lower CAS climb, a higher crossover altitude (around FL360) is found, were climb resumes ad constant Mach number (also lower than the nominal one).

Results in Case-3 show that the climb speed profile is the same with the one in Case-2, except for the constant Mach climb segment, as the crossover altitude for this flight is higher than its optimal cruise flight level (FL360). Due to this lower final altitude of climb, the fuel consumption decreases to $1780 \mathrm{~kg}$, corresponding to an avg. TAS of $321 \mathrm{kt}$ which, however, is higher than the $317 \mathrm{kt}$ in Case-2 (see Table 1), so the LH time in climb will not be as much as that in Case-2.

As for the descent speed profiles shown in Fig. 14(b), Case-2 and Case-3 have no deceleration process at FL100 (like in Case-0 and Case-1) because the descent speed is already below the ATC constraint of CAS lower than 250kt below FL100. Moreover, the segments of constant Mach descent are both missing too, since the crossover altitudes lay higher above the cruise flight levels due to the lower speeds in constant CAS descent.

Normally, the fuel consumption in descent phase accounts for the lowest 
of the three phases, but it still generates a high percentage of LH with regard to the total descent time in the above example. Similar situation as in climb, with a deceleration at the initial of descent, Case- 1 has an avg. TAS of $307 \mathrm{kt}$ lower than the nominal one at 323kt, while in Case-2 with descent CAS declining to near the GD speed, the avg. TAS reduces further to $265 \mathrm{kt}$ and some fuel are saved (see Table 1).

In Case-3, the descent CAS keeps decreasing and reaches the GD speed for this flight (see Fig. 14(b)). Remember the GD speed is not the same in climb that in descent, since the aircraft mass is different (fuel has been burnt in cruise). It is worth noting that after the reduction of cruise flight level in Case-3, the fuel consumption of descent increases instead, compared with Case-2, which is on the contrary of the situation in climb. In this way, the avg. TAS further reduces to $237 \mathrm{kt}$ in order to produce a longer LH time (see Table 1).

When it comes to the cruise phase, as shown in Fig. 14(c), if LH is realized only in this phase as Case-1, then the cruise Mach decreases from M0.79 to M0.72, while after climb and descent phases are involved in LH, the cruise speed keeps decreasing to M0.7 and M0.66 in Case-2 and Case-3, respectively, resulted from the lower SR (extra fuel "allowance" due to savings in climb/descent), as also seen in Table 1. If the curve of SR becomes flatter when speed is lower than the equivalent speed (see Fig. 6), it happens that a slightly decrease in SR could bring a relative larger decrease in cruise speed, by which a remarkable amount of LH time can be produced, considering the long distance and time that cruise phase could take.

\section{Conclusions}

In this paper, a LH strategy was proposed on basis of previous works where linear holding was only allowed by reducing cruise speed (Delgado and Prats (2012); Delgado et al. (2013); Delgado and Prats (2013, 2014)). By analyzing the relationship between fuel consumption and speed in each flight phase, the equivalent speed concept was extended to the climb and descent phases, and thus the speed reduction proved to be feasible to be implemented along the whole flight to generate LH at no extra fuel cost. Through a detailed simulation on typical flights with the developed optimal trajectory generation tool, the effects of three subdivided Cases of the LH strategy were thoroughly assessed, where a remarkable increase of the maximum airborne delay absorption was observed compared with previous studies. 
Results suggest that the difference of trade-off between fuel and time in each flight phase (even in flight segments within a particular phase) contributes to the remarkable amounts of LH. For instance, all the trajectories in simulation are observed to consume more fuel in the descent phase to produce airborne delay, and (only) in Case-3 the fuel are all saved in the climb phase with negative delay generated.

Besides, a specific transition of fuel, e.g., from climb to cruise phase, like the case in Sec. 4.2, may not be a general pattern that satisfies all the cases, but the reallocation of fuel among different flight phases does exist generally. Including climb and descent would make it possible for the optimizer to utilize these differences on trade-off to maximize the total LH. Nevertheless, the implicit characteristics of these trade-offs still require a further analysis by performing more simulation experiments, as they might have direct effects on the speed recovery process which contributes to one of the main advantages of the LH strategy.

The significant increase in Case-2 (when LH is allowed in climb and descent) indicates that it be possible to have much delay absorbed airborne without changing the initial flight plan, raising an interesting question on how to properly implement the LH strategy at tactical level whilst meeting the potential needs to such as handle traffic uncertainties, organize traffic flow, recover flight speed, and be compatible with terminal ATM procedures. These aspects deserve a further research in future.

Finally, future work will also aim at the applicability of LH in realistic scenarios. Besides the constraints of fuel consumption, more conditions should be taken into consideration along with the implement of $\mathrm{LH}$, such as the slots allocation in particular designated waypoints and the weather (wind) effects around specific airspace for instances. In addition, given a situation that the time related costs for airlines may increase sharply than the costs of fuel after distributed really long time delays, a limited margin on extra fuel consumption than initially planned could probably be allowed eventually.

\section{Acknowledgment}

The authors would like to thank Airbus Industrie for the use of PEP (Performance Engineers Program) suite, which allowed us to undertake realistic aircraft performances simulations. This research is partially supported by grants from the Funds of China Scholarship Council (201506830050). The 
authors would like to thank the reviewers and the editor for their comments that have improved the paper.

Airbus, 1993a. Flight Crew Operation Manual (FCOM). A320. Version 1.3.1.

Airbus, 1993b. Flight Crew Operation Manual (FCOM): A320, Version 1.3.1.

Airbus, 1998. Getting to grips with the cost index, Issue II. Flight Operations Support and Line Assistance (STL), Customer Services Directorate, Blagnac.

Australia, A., 2007. Annual report. Tech. rep.

Ball, M. O., Hoffman, R., Mukherjee, A., 2010. Ground delay program planning under uncertainty based on the ration-by-distance principle. Transportation Science 44 (1), 1-14.

Barmore, B., 2006. Airborne precision spacing: A trajectory-based aprroach to improve terminal area operations. In: Proceedings of the 2006 IEEE/AIAA 25th Digital Avionics Systems Conference. IEEE, pp. 1-12.

Belkoura, S., Peña, J. M., Zanin, M., 2016. Generation and recovery of airborne delays in air transport. Transportation Research Part C: Emerging Technologies 69, 436-450.

Betts, J. T., 2010. Practical methods for optimal control and estimation using nonlinear programming. Vol. 19. SIAM.

Bilimoria, K., 2016. Analysis of additional delays experienced by flights subject to ground holding. In: Proceedings of the AIAA Aviation Technology, Integration, and Operations Conference.

Cook, A. J., Tanner, G., 2011. European airline delay cost reference values.

Cook, L. S., Wood, B., 2010. A model for determining ground delay program parameters using a probabilistic forecast of stratus clearing. Air traffic control quarterly 18 (1), 85.

Dalmau, R., Prats, X., 2015. Fuel and time savings by flying continuous cruise climbs: Estimating the benefit pools for maximum range operations. Transportation Research Part D: Transport and Environment 35, 62-71. 
Delgado, L., Martin, J., Blanch, A., Cristóbal, S., 2016. Hub operations: delay recovery based on cost optimisation. In: Proceedings of the 6th SESAR Innovation Days.

Delgado, L., Prats, X., 2012. En route speed reduction concept for absorbing air traffic flow management delays. Journal of Aircraft 49 (1), 214-224.

Delgado, L., Prats, X., 2013. Effect of wind on operating-cost-based cruise speed reduction for delay absorption. Intelligent Transportation Systems, IEEE Transactions on 14 (2), 918-927.

Delgado, L., Prats, X., 2014. Operating cost based cruise speed reduction for ground delay programs: Effect of scope length. Transportation Research Part C: Emerging Technologies 48, 437-452.

Delgado, L., Prats, X., Sridhar, B., 2013. Cruise speed reduction for ground delay programs: A case study for san francisco international airport arrivals. Transportation Research Part C: Emerging Technologies 36, 83-96.

FAA, 2015. Instrument Procedures Handbook, FAA-H-8083-16A, Chapter 3, Arrivals.

Günther, T., Fricke, H., 2006. Potential of speed control on flight efficiency. In: Proceedings of the 2nd International Conference on Research in Air Transportation (ICRAT). Vol. 1. pp. 197-201.

Inniss, T. R., Ball, M. O., 2004. Estimating one-parameter airport arrival capacity distributions for air traffic flow management. Air Traffic Control Quarterly 12, 223-252.

Jones, J. C., Lovell, D. J., Ball, M. O., 2013. En route speed control methods for transferring terminal delay. In: Proceedings of the 10th USA/Europe Air Traffic Management Research and Development Seminar.

Jones, J. C., Lovell, D. J., Ball, M. O., 2015. Combining control by cta and dynamic en route speed adjustment to improve ground delay program performance. In: Proceedings of the 11th USA/Europe Air Traffic Management Research and Development Seminar.

Kirkman, W., Gaydos, T., Weitz, L., 2014. Optimizing metering for trajectory timing uncertainty. In: Proceedings of the AIAA Guidance, Navigation, and Control Conference. 
Klooster, J., Torres, S., Earman, D., Castillo-Effen, M., Subbu, R., Kammer, L., Chan, D., Tomlinson, T., 2010. Trajectory synchronization and negotiation in trajectory based operations. In: Proceedings of the IEEE/AIAA 25th Digital Avionics Systems Conference. IEEE.

Klooster, J. K., Del Amo, A., Manzi, P., 2009. Controlled time-of-arrival flight trials. In: Proceedings of the 8th USA/Europe Air Traffic Management Research and Development Seminar.

Organization, I. C. A., 1994. Manual of the ICAO Standard Atmosphere: Extended to 80 Kilometres (262 500 Feet). International Civil Aviation Organization.

Prats, X., Hansen, M., 2011. Green delay programs: absorbing atfm delay by flying at minimum fuel speed. In: Proceedings of the 9th USA/Europe air traffic management R\&D seminar, Berlin, Germany.

Richetta, O., 1991. Ground holding strategies for air traffic control under uncertainty. Ph.D. thesis, Massachusetts Institute of Technology.

Roberson, B., Pilot, S. S., 2007. Fuel conservation strategies: cost index explained. Boeing Aero Quarterly 2, 26-28.

Ruiz, S., Piera, M. A., Nosedal, J., Ranieri, A., 2014. Strategic de-confliction in the presence of a large number of $4 \mathrm{~d}$ trajectories using a causal modeling approach. Transportation Research Part C: Emerging Technologies 39, $129-147$.

Smedt, D. d., Bronsvoort, J., McDonald, G., 2013. Controlled time of arrival feasibility analysis. In: Proceedings of the 10th USA/Europe Air Traffic Management Research and Development Seminar.

Tomlin, C., Pappas, G. J., Sastry, S., 1998. Conflict resolution for air traffic management: A study in multiagent hybrid systems. IEEE Transactions on automatic control 43 (4), 509-521.

Vela, A., Solak, S., Singhose, W., Clarke, J.-P., 2009. A mixed integer program for flight-level assignment and speed control for conflict resolution. In: Proceedings of the 48th IEEE Conference on Decision and Control. IEEE, pp. 5219-5226. 
Xu, Y., Prats, X., 2017. Effects of linear holding for reducing additional flight delays without extra fuel consumption. Transportation Research Part D: Transport and Environment 53, 388-397.

Xu, Y., Zhang, H., Liao, Z., Yang, L., 2016. A dynamic air traffic model for analyzing relationship patterns of traffic flow parameters in terminal airspace. Aerospace Science and Technology 55, 10-23. 


\begin{abstract}
This paper introduces a linear holding strategy based on prior works on cruise speed reduction, aimed at performing airborne delay at no extra fuel cost, as a complementary strategy to current ground and airborne holding strategies. Firstly, the equivalent speed concept is extended to climb and descent phases through an analysis of fuel consumption and speed from aircraft performance data. This gives an insight of the feasibility to implement the concept, differentiating the case where the cruise flight level initially requested is kept and the case where it can be changed before departure in order to maximise the linear holding time. Illustrative examples are given, where typical flights are simulated using an optimal trajectory generation tool where linear holding is maximised while keeping constant the initially planned fuel. Finally, the effects of linear holding are thoroughly assessed in terms of the vertical trajectory profiles, range of feasible speed intervals and trade-offs between fuel and time. Results show that the airborne delay increases significantly with nearly 3 -fold time for short-haul flights and 2-fold for mid-hauls to the cases in prior works.
\end{abstract}




\section{Keywords}

air transportation, linear holding, speed reduction, trajectory optimization, air traffic flow management. 


\section{Figures captions}

Fig. 1 A comparison between ground holding, airborne holding and linear holding.

Fig. 2 Specific range as a function of cruise speed. Source: Delgado and Prats (2012).

Fig. 3 Fuel consumption as a function of climb/descent speed.

Fig. 4 Effects of different climb/descent speeds to vertical flight profile.

Fig. 5 Typical operational climb and descent speed profiles.

Fig. 6 Cruise specific range vs. Mach for different cruise flight levels.

Fig. 7 Main architecture of the trajectory optimization tool.

Fig. 8 Model for the vertical profile used in the trajectory optimization tool.

Fig. 9 Airborne delay generated for the simulated trajectories.

Fig. 10 The changes of fuel consumption in each flight phase (defined by TOC/TOD) compared to Case- 0 for the simulated trajectories.

Fig. 11 Airborne delay versus difference on fuel consumption of each flight phase (defined by TOC/TOD and Ref. TOC/TOD) with respect to the nominal flight (Case-0).

Fig. 12 Vertical and true airspeed (TAS) profiles.

Fig. 13 Airborne delay and fuel difference change along flight distance with respect to the nominal trajectory (Case-0).

Fig. 14 Climb, cruise and descent speed profiles for the FRA-MAD (CI $=60 \mathrm{~kg} / \mathrm{min}$ ). 


\section{Table captions}

Table 1 Main trip parameters for the FRA-MAD with $\mathrm{CI}=60 \mathrm{~kg} / \mathrm{min}$. 


\section{Figures and Tables}

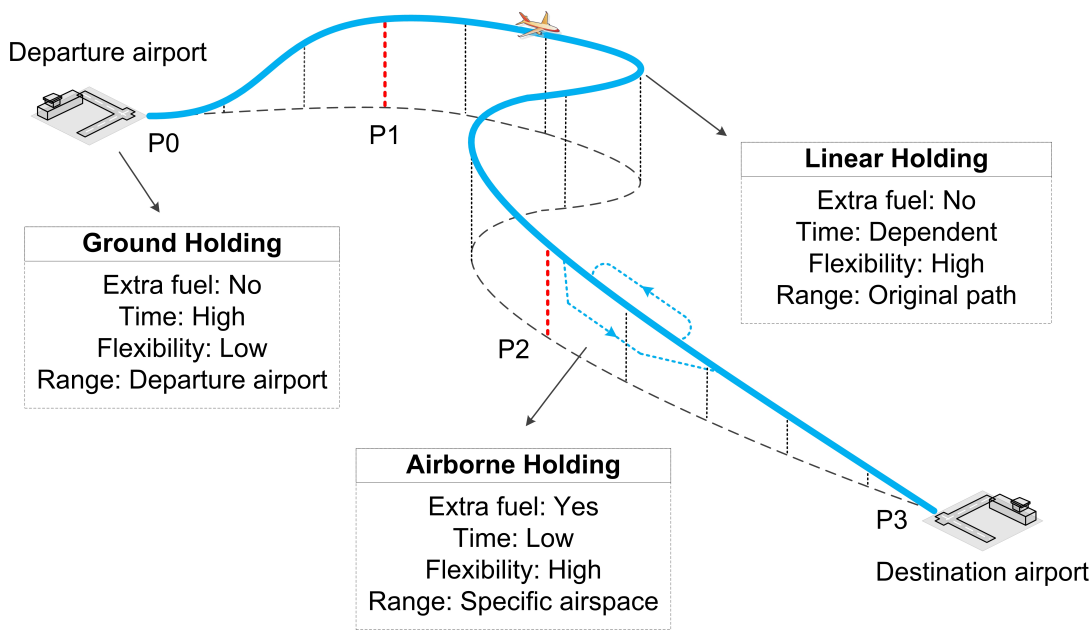

Figure 1: A comparison between ground holding, airborne holding and linear holding.

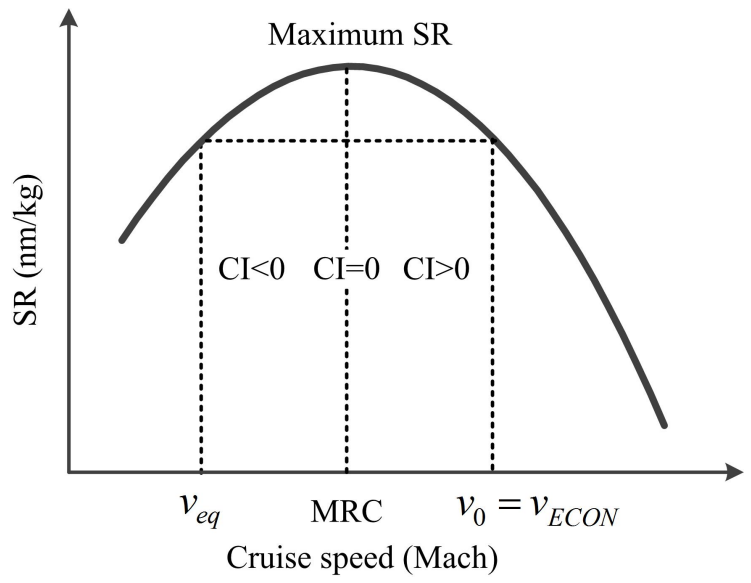

Figure 2: Specific range as a function of cruise speed. Source: Delgado and Prats (2012). 


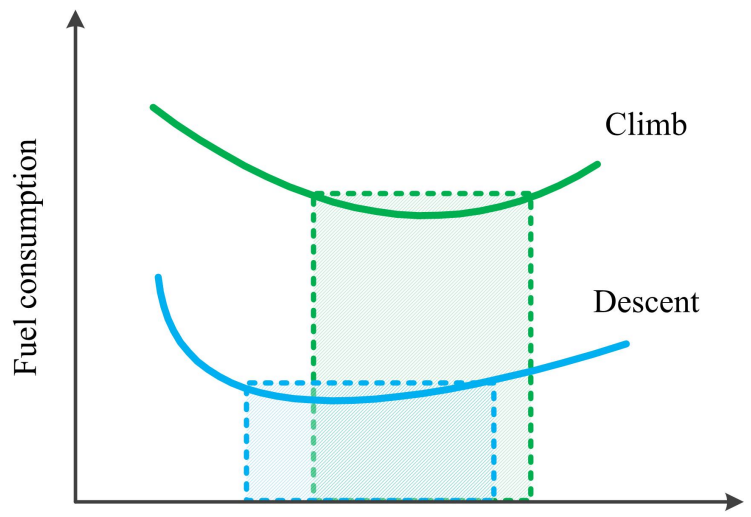

Equivalent speeds Nominal speeds

Figure 3: Fuel consumption as a function of climb/descent speed.

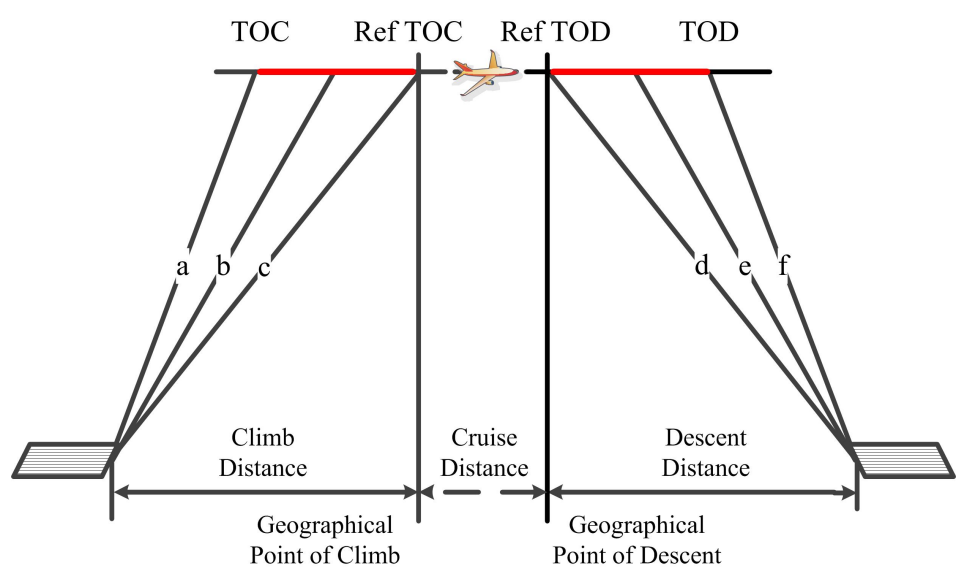

Figure 4: Effects of different climb/descent speeds to vertical flight profile. 


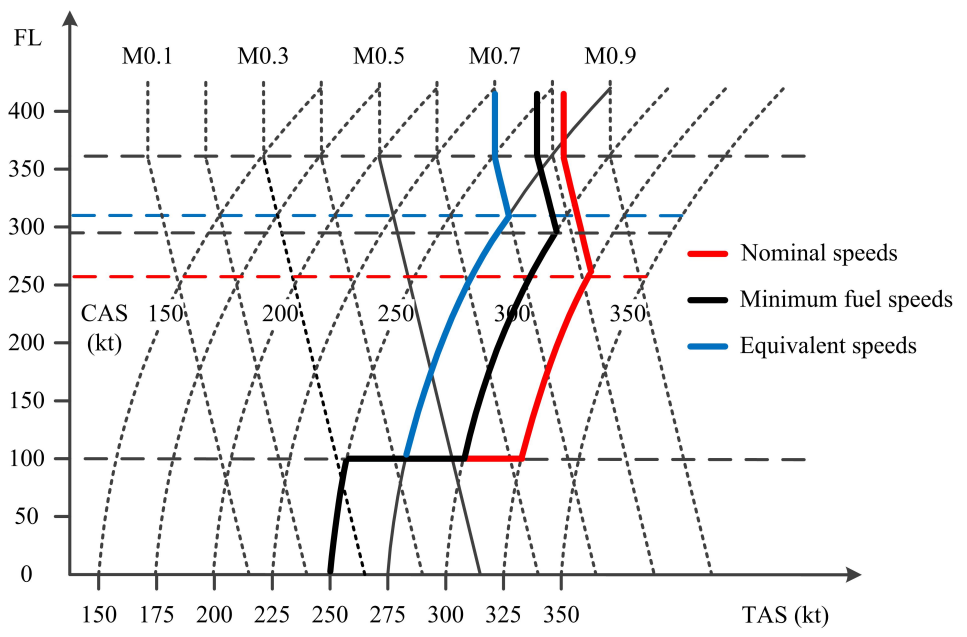

Figure 5: Typical operational climb and descent speed profiles.

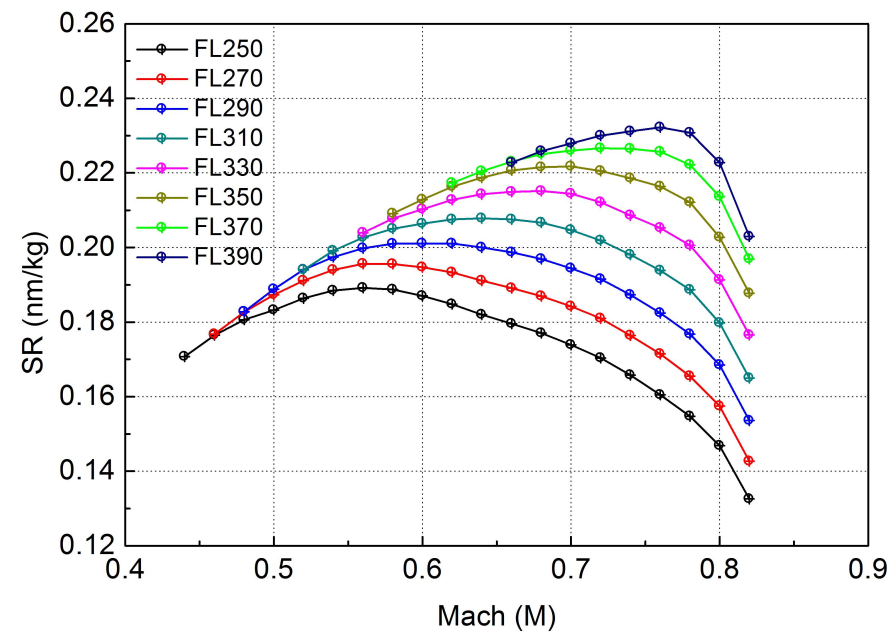

Figure 6: Cruise specific range vs. Mach for different cruise flight levels. 


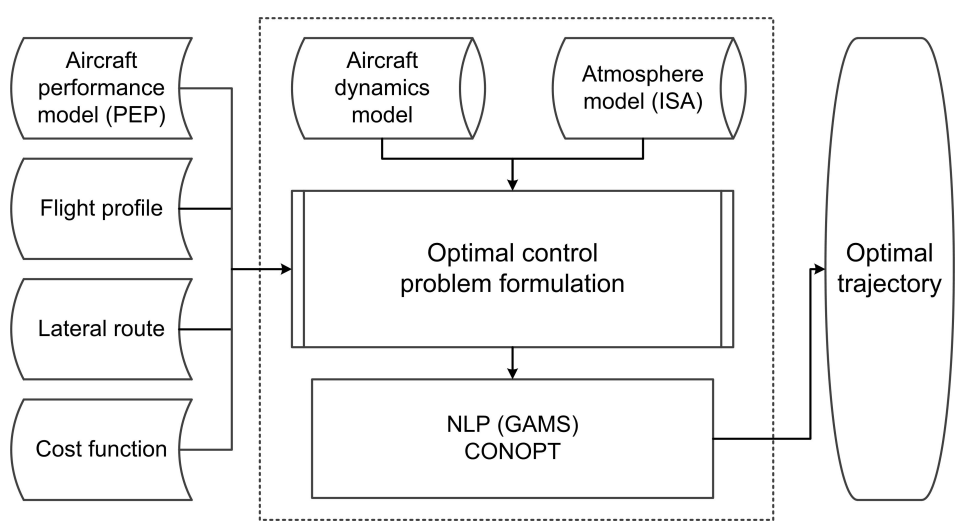

Figure 7: Main architecture of the trajectory optimization tool.

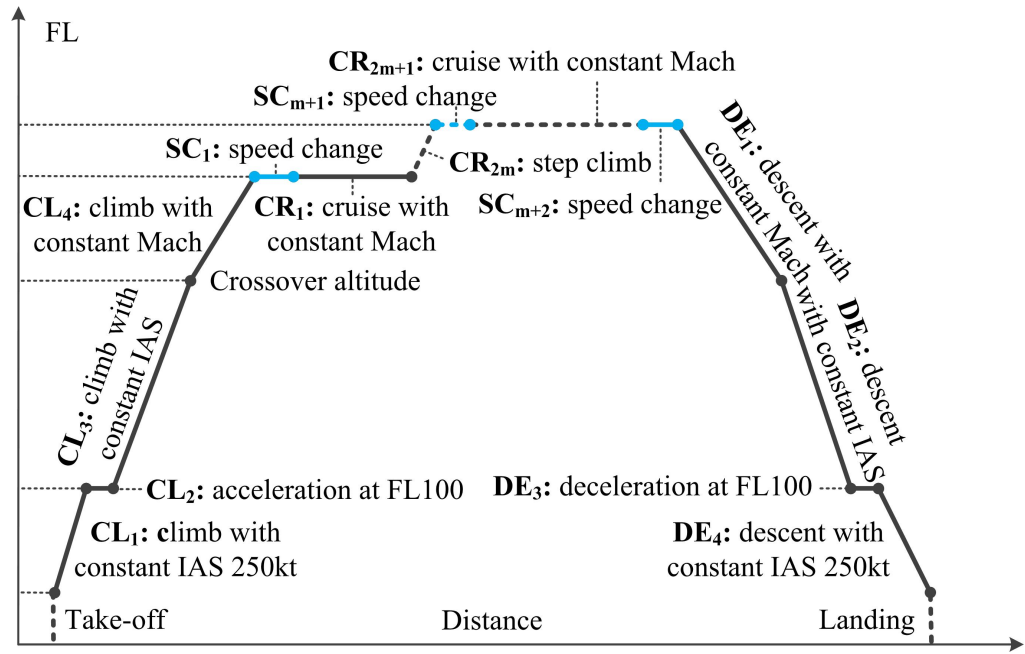

Figure 8: Model for the vertical profile used in the trajectory optimization tool.

Note: the dash line in cruise phase means possible step climb cruise, which could be more than once. The subscript $m$ is the ordinal number of the step climb cruise and equals to $0,1, \cdots, \mathrm{n}$. 


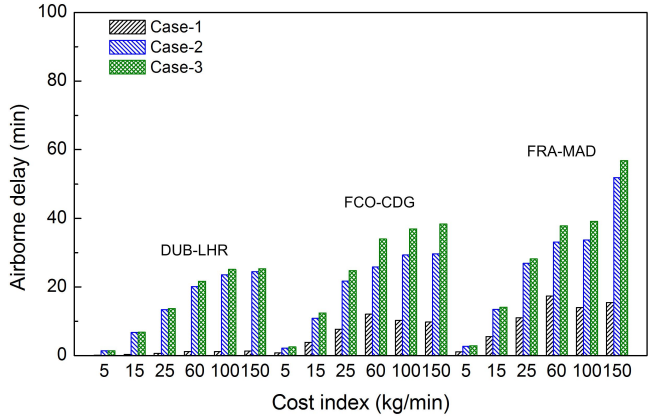

(a) Short-haul flights

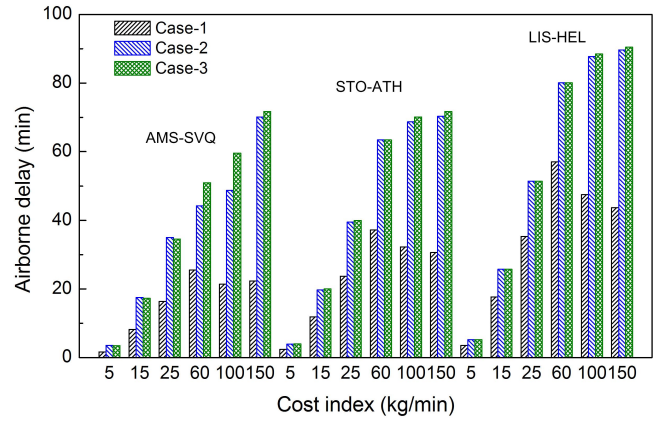

(b) Mid-haul flights

Figure 9: Airborne delay generated for the simulated trajectories.

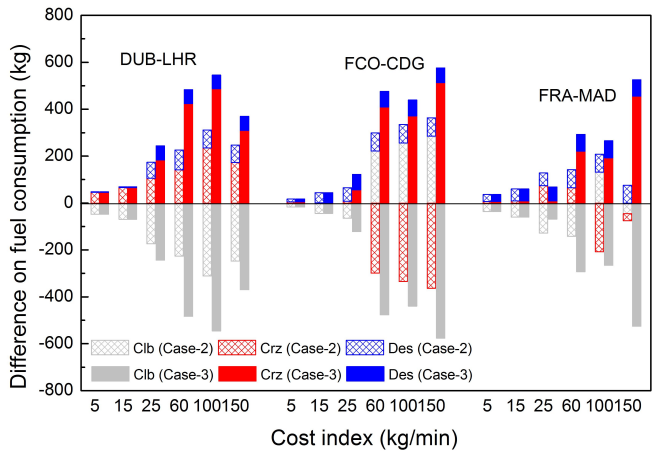

(a) Short-haul flights

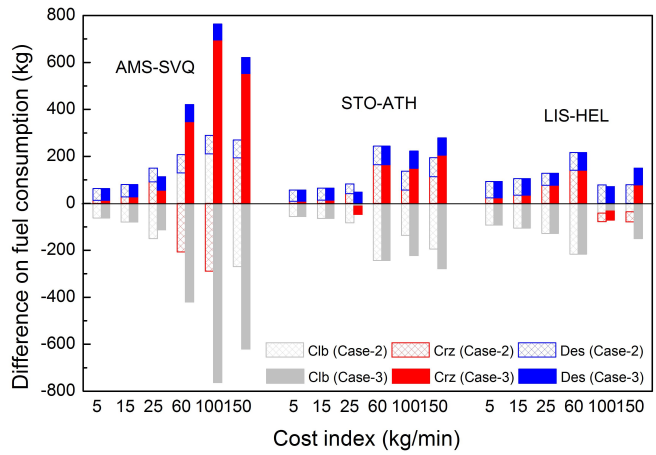

(b) Mid-haul flights

Figure 10: The changes of fuel consumption in each flight phase (defined by TOC/TOD) compared to Case-0 for the simulated trajectories. 


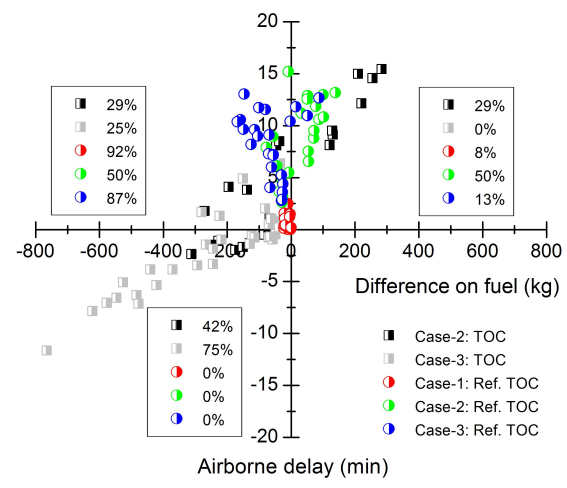

(a) Climb phase

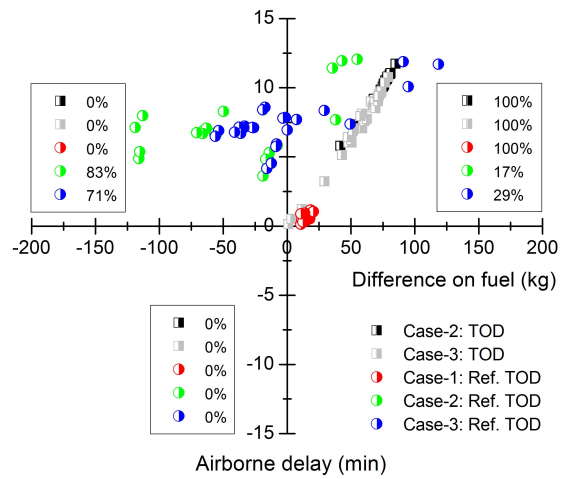

(c) Descent phase

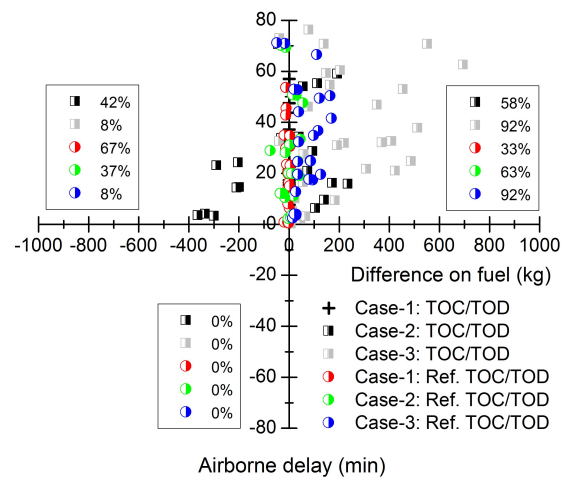

(e) Cruise phase

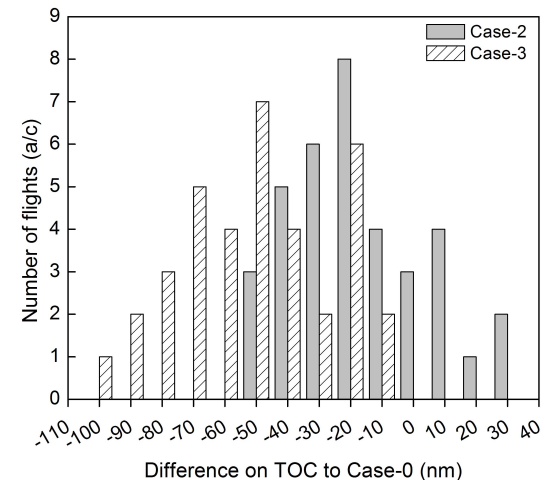

(b) TOC distance

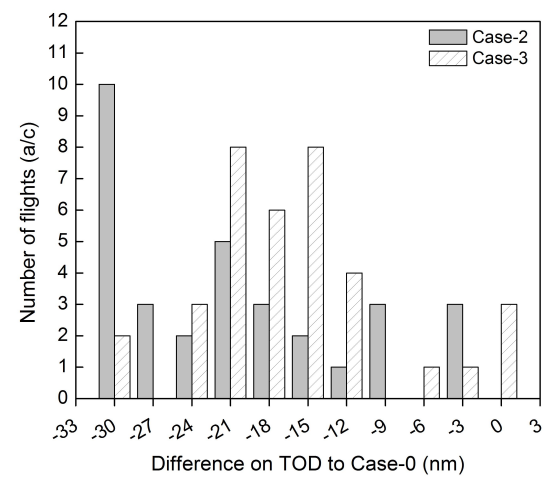

(d) TOD distance

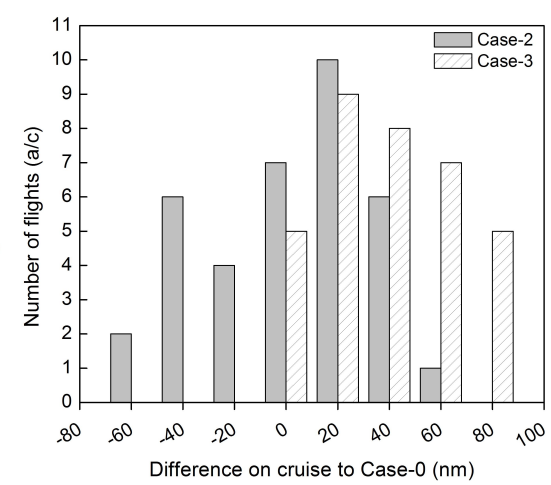

(f) Cruise distance

Figure 11: Airborne delay versus difference on fuel consumption of each flight phase (defined by TOC/TOD and Ref. TOC/TOD) with respect to the nominal flight (Case-0). 


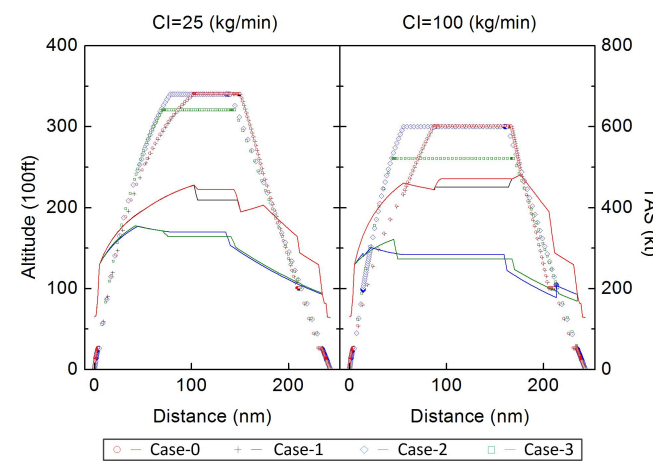

(a) DUB-LHR

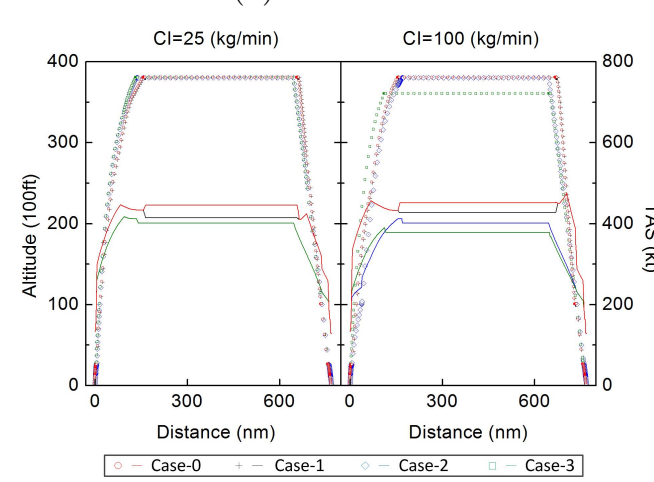

(c) FRA-MAD

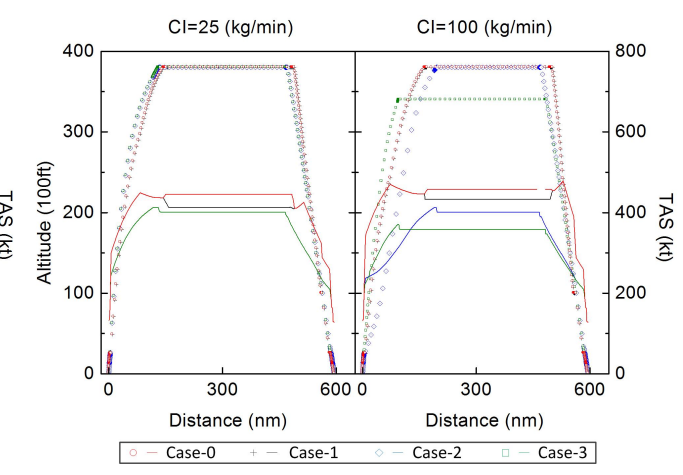

(b) FCO-CDG

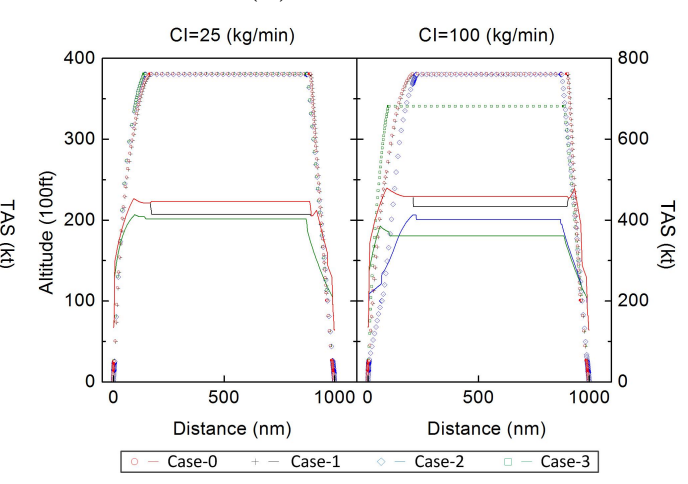

(d) AMS-SVQ

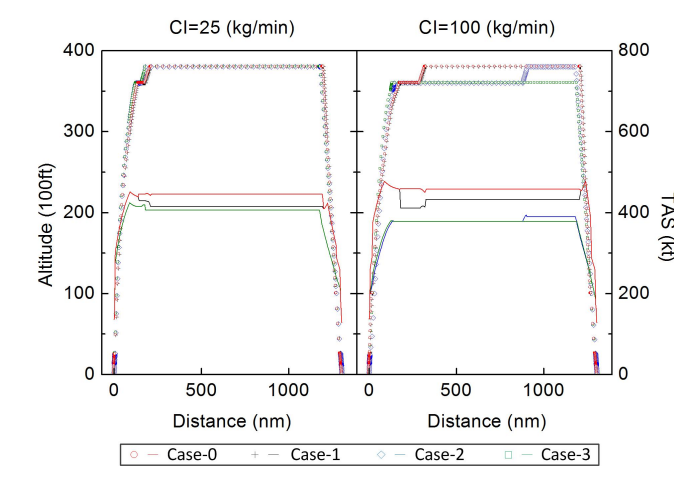

(e) STO-ATH

Figure 12: Vertical and true airspeed (TAS) profiles. 


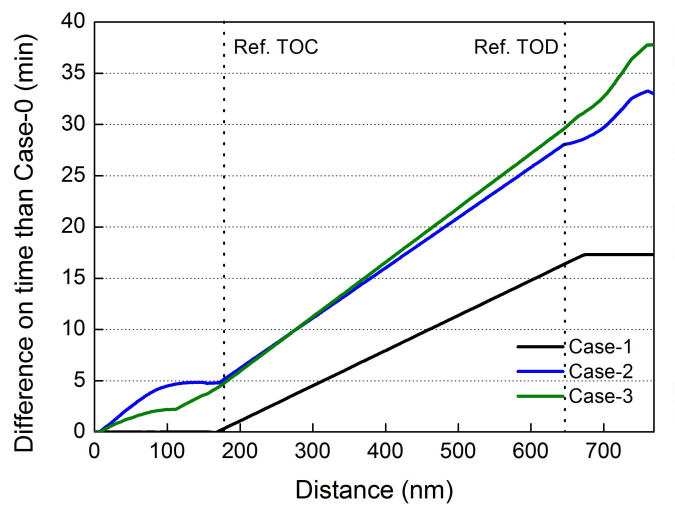

(a) Airborne delay

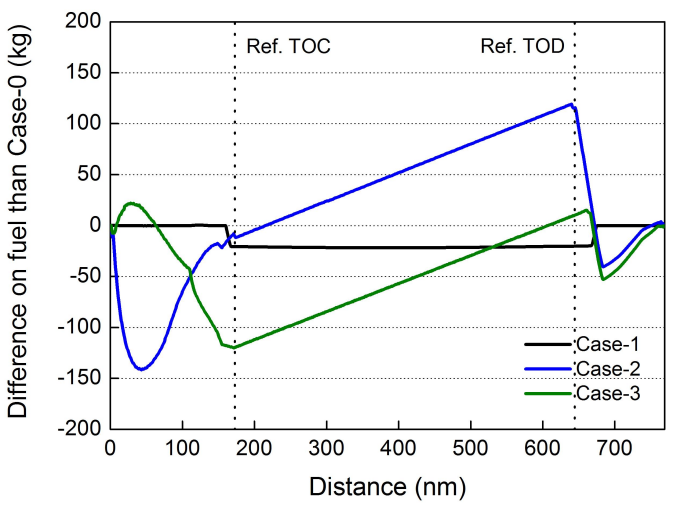

(b) Fuel consumption

Figure 13: Airborne delay and fuel difference change along flight distance with respect to the nominal trajectory (Case- 0 ).

Table 1: Main trip parameters for the FRA-MAD with $\mathrm{CI}=60 \mathrm{~kg} / \mathrm{min}$.

\begin{tabular}{|c|c|c|c|c|c|c|c|c|c|c|}
\hline \multirow{2}{*}{ Cases } & \multicolumn{5}{|c|}{$\begin{array}{c}\text { Climb } \\
\text { (Ref TOC 171nm) }\end{array}$} & \multicolumn{5}{|c|}{$\begin{array}{c}\text { Descent } \\
\text { (Ref TOD 124nm) }\end{array}$} \\
\hline & $\begin{array}{l}\text { Fuel } \\
(\mathrm{kg})\end{array}$ & $\begin{array}{l}\text { Time } \\
(\mathrm{min})\end{array}$ & $\begin{array}{l}\text { Avg.TAS } \\
\text { (kt) }\end{array}$ & $\begin{array}{l}\text { Dif. Fuel } \\
\quad(\mathrm{kg})\end{array}$ & $\begin{array}{l}\text { LH } \\
(\min )\end{array}$ & $\begin{array}{l}\text { Fuel } \\
(\mathrm{kg})\end{array}$ & $\begin{array}{l}\text { Time } \\
(\mathrm{min})\end{array}$ & $\begin{array}{l}\text { Avg.TAS } \\
\text { (kt) }\end{array}$ & $\begin{array}{l}\text { Dif. Fuel } \\
(\mathrm{kg})\end{array}$ & $\begin{array}{l}\mathrm{LH} \\
(\min )\end{array}$ \\
\hline Case-0 & 1900 & 27.5 & 372 & - & - & 389 & 23.1 & 323 & & - \\
\hline Case-1 & 1881 & 28.1 & 365 & -19 & 0.6 & 375 & 24.3 & 307 & -14 & 1.2 \\
\hline Case-2 & 1893 & 32.4 & 317 & -7 & 4.8 & 275 & 28.1 & 265 & -115 & 5.0 \\
\hline Case-3 & 1780 & 32.0 & 321 & -120 & 4.4 & 380 & 31.4 & 237 & -9 & 8.3 \\
\hline \multirow{2}{*}{ Cases } & \multicolumn{5}{|c|}{$\begin{array}{c}\text { Cruise } \\
\text { (Ref } 474 \mathrm{~nm})\end{array}$} & \multicolumn{5}{|c|}{ Whole flight $(769 \mathrm{~nm})$} \\
\hline & $\begin{array}{l}\text { Alt. } \\
\text { (FL) }\end{array}$ & $\begin{array}{l}\text { Fuel } \\
(\mathrm{kg})\end{array}$ & $\begin{array}{l}\text { Time } \\
(\mathrm{min})\end{array}$ & $\begin{array}{c}\mathrm{SR} \\
(\mathrm{nm} / \mathrm{kg})\end{array}$ & $\begin{array}{l}\text { Avg.TAS } \\
\text { (kt) }\end{array}$ & $\begin{array}{l}\text { Dif. Fuel } \\
\quad(\mathrm{kg})\end{array}$ & $\begin{array}{l}\mathrm{LH} \\
(\mathrm{min})\end{array}$ & $\begin{array}{l}\text { Fuel } \\
(\mathrm{kg})\end{array}$ & $\begin{array}{l}\text { Time } \\
(\min )\end{array}$ & $\begin{array}{l}\mathrm{LH} \\
(\min )\end{array}$ \\
\hline Case-0 & 380 & 2200 & 59.5 & 0.2154 & 478 & - & - & 4490 & 110.1 & - \\
\hline Case-1 & 380 & 2234 & 75.0 & 0.2122 & 379 & 33 & 15.5 & 4490 & 127.4 & 17.3 \\
\hline Case-2 & 380 & 2323 & 82.7 & 0.2041 & 344 & 122 & 23.2 & 4490 & 143.2 & 33.0 \\
\hline Case-3 & 360 & 2330 & 84.7 & 0.2035 & 336 & 129 & 25.1 & 4490 & 148.0 & 37.8 \\
\hline
\end{tabular}




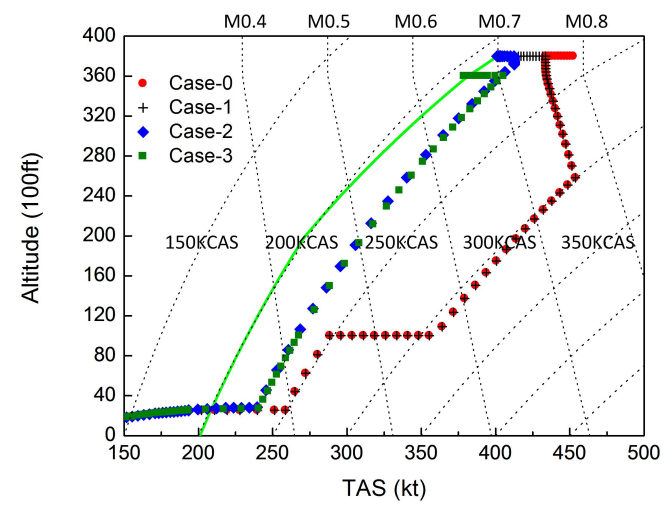

(a) Climb phase

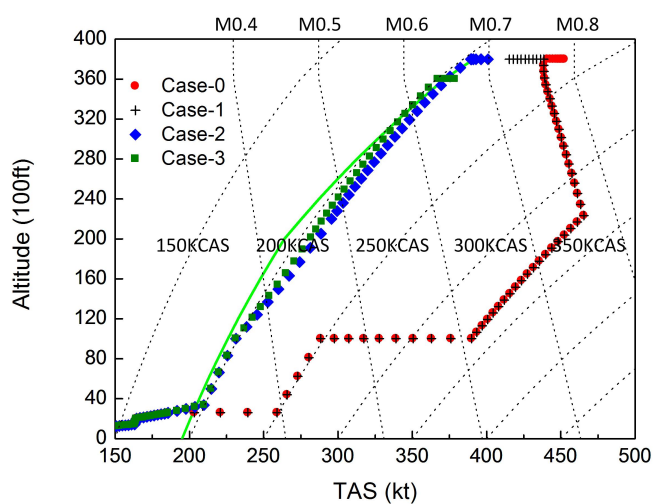

(b) Descent phase

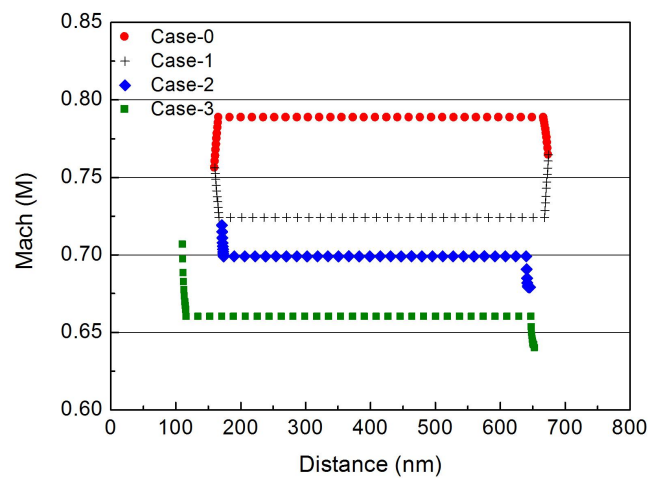

(c) Cruise phase

Figure 14: Climb, cruise and descent speed profiles for the FRA-MAD $(\mathrm{CI}=60 \mathrm{~kg} / \mathrm{min})$. 